NASA Technical Memorandum 107280

AIAA-96-3234

\title{
Nanoparticulate Gellants for Metallized Gelled Liquid Hydrogen With Aluminum
}

John Starkovich and Scott Adams

TRW Space and Electronics Group

Redondo Beach, California

Bryan Palaszewski

Lewis Research Center

Cleveland, Ohio

Prepared for the

32nd Joint Propulsion Conference and Exhibit cosponsored by AIAA, ASME, SAE, and ASEE

Lake Buena Vista, Florida, July 1-3, 1996

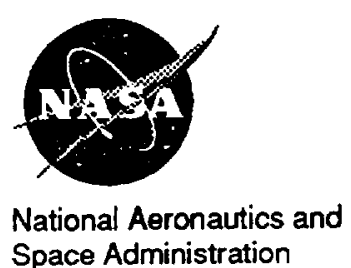

Space Administration 


\section{.}




\title{
NANOPARTICULATE GELLANTS \\ FOR METALLIZED GELLED LIQUID HYDROGEN WITH ALUMINUM
}

\author{
Drs. John Starkovich and Scott Adams \\ TRW Space and Electronics Group \\ Redondo Beach, CA \\ Bryan Palaszewski* \\ NASA Lewis Research Center \\ Cleveland, $\mathrm{OH}$
}

\begin{abstract}
Gelled liquid hydrogen was

experimentally formulated using sol-gel

technology. As a follow-on to work with

cryogenic simulants, hydrogen was gelled with

an alkoxide material: BTMSE. Initial results

demonstrated that gellants with a specific

surface area of $1000 \mathrm{~m}^{2} / \mathrm{g}$ could be repeatably

fabricated. Gelled hexane and metallized gelled

hexane (with 13.8- wt\% Al) were produced.

Propellant settling testing was conducted for

acceleration levels of 2 to 10 times normal

gravity and a minimum gellant percentage was

determined for stable gelled hexane and

metallized gelled hexane. A cryogenic capillary

rheometer was also designed, constructed, and

used to determine the viscosity of gelled

hydrogen. Small volumes of liquid hydrogen

were gelled with a 7- to 8-wt\% gellant level.

The gelled $\mathrm{H}_{2}$ viscosity was 1.5 to 3.7 times

that of liquid hydrogen: 0.048 to $0.116 \mathrm{mPa}-\mathrm{s}$

versus $0.03 \mathrm{mPa}$-s for liquid $\mathrm{H}_{2}$ (at $16 \mathrm{~K}$ and

approximately $1 \mathrm{~atm}$ pressure).
\end{abstract}

Nomenclature

BET Brunauer-Emmett-Teller surface area measurement

BTMSE Alkoxides with Ethyl

Hydrocarbons

$\mathrm{CO}_{2} \quad$ Carbon Dioxide

$\mathrm{H}_{2} / \mathrm{Al} \quad$ Hydrogen /Aluminum

GLOW Gross Lift Off Weight

$I_{\text {sp }}$

$\mathrm{K}$

Specific Impulse $\left(\mathrm{lb}_{\mathrm{f}}-\mathrm{s} / \mathrm{/} \mathrm{b}_{\mathrm{m}}\right)$

Temperature in Kelvin

MMH/Al Monomethyl Hydrazine

/Aluminum

NASA National Aeronautics and Space

Administration

NTO Nitrogen Tetroxide

$\mathrm{O}_{2} / \mathrm{H}_{2} \quad$ Oxygen $/$ Hydrogen

$\mathrm{P} \quad$ Expulsion Pressure

PZT Piezoelectric

O Mass Flow Rate

RP-1 /Al Rocket Propellant-1 /Aluminum

TEOS Tetraethyl Orthosilicate

wt\% Weight Percent (of additive)

* AIAA Senior Member, Program Manager, Fuels and Space Propellants for Reusable Launch Vehicles - Small Business Innovation Research (SBIR) Focused Topic 


\section{Introduction}

An experimental program was conducted to produce gelled liquid hydrogen with nanoparticulate materials. These materials have a high surface area per unit mass and can potentially reduce the total mass of gellant needed to form a gel structure in the liquid hydrogen. Both hydrogen and hexane were gelled with new gellants produced from alkoxide materials that have a specific surface area of $1000 \mathrm{~m}^{2} / \mathrm{g}$. In addition to formulating the gelled fuels, a cryogenic rheometer was built and used to determine the viscosity of the gelled hydrogen. Syneresis or settling tests were also conducted with gelled and metallized gelled hexane.

Gelled propellants require a gellant that maintains a viscous thixotropic nature for an extended time. In metallized gelled fuels, dense metal particles are dispersed homogeneously throughout the fluid, and they must remain uniformly distributed in the liquid propellant during storage and transport. The distribution of particles is achieved by proper mixing, while the particle suspension can be maintained by gelling the metallized fuel. The gelation of $\mathrm{H}_{2}$ fuel was successfully demonstrated in earlier NASA studies. 1 - 5 However, the studies of cryogenic fuels employed high loadings of frozen cryogens such as ethane or methane (10 to $20 \mathrm{wt} \%$ ) or silica particles (10 to $40 \mathrm{wt} \%$ of the fuel) to prevent the metal particles from settling. Based on mission studies, the lowest gellant weight \% is desired to maximize engine performance. The frozen cryogens add combustion energy to the fuel, but gelled hydrogen is often less energetic than pure hydrogen. However, the large fraction of silica gellant required does not make the hydrogen combustion process more energetic, making these type of gelled propellants impractical for propulsion applications. More efficient gellants that provide higher combustion energy are desirable.

The silica gellant materials employed in earlier studies (Tetraethyl Orthosilicate or TEOS) were produced pyrogenically and have nominal surface areas and particle diameters of approximately $100 \mathrm{~m}^{2}$ and $15 \mathrm{~nm}$, respectively. 6,7 The higher surface area translates into higher gelling efficiency, and therefore less gellant is used. These smaller dimension gellant particles may be prepared using sol-gel synthesis procedures and advanced processing methods.6, 7 In particular, tailored organic polymers are attractive candidate gelling agents since these materials are efficient gelling agents for nonpolar liquids and they contribute energy to the combustion of the cryogenic gel propellants.

\section{Background}

Gelled rocket propellants have been considered for many different applications. $1-14$ While operational usage has not yet come to fruition, there are many technology programs that are underway to eliminate the unknowns with gelled propellants and the propulsion systems that will use them. Numerous studies have shown the potential benefits of gelled fuels and oxidizers. Technology programs to prove the combustion performance of gelled propellants have been conducted most recently by the U.S. Army Missile Command, with their industry and university partners, for tactical missile applications. The NASA Lewis Research Center and its partners have investigated $\mathrm{O}_{2} / \mathrm{H}_{2} / \mathrm{Al}$ and $\mathrm{O}_{2} / \mathrm{RP}-1 / \mathrm{Al}$ for NASA missions and conducted experimental programs to validate elements of the combustion and fuel technology. Gelled and metallized gelled hydrogen and RP-1 have been emphasized because hydrogen and RP-1 are typical propellants for NASA launch vehicles and upper stages. Derivatives of these propellants are therefore preferred to minimize the incremental risk for a newly introduced propulsion concept. Gelled hydrogen technology is emphasized in this paper. Its likely applications would be for rocket powered launch vehicles and upper stages, rocket based combined cycle airbreathing vehicles, and combination (rocket and airbreathing) propulsion options. ${ }^{8-17}$ 


\section{Why Gelled Hydrogen?}

The benefits of gelled hydrogen have been known for many years and experimentally proven in the past.1-5 There are five major benefits: safety increases, boiloff reductions, density increases with the attendant area and volume related mass reductions for related subsystems (thermal protection system, structure, insulation, etc.), slosh reductions, and specific impulse $\left(I_{\text {sp }}\right)$ increases (in some cases).

Safety can be significantly increased with gelled fuels. A higher viscosity reduces the spill radius of the gelled hydrogen and limits the potential damage and hazard from a fuel spill. Another important advantage is the potential for leak reduction or elimination. The leak paths from the feed systems would be minimized and the possible explosion potential would be reduced.

Boiloff reduction is another feature of gelled hydrogen. The boiloff reductions are up to a factor of 2 to 3 over ungelled liquid hydrogen.8, 13, 14 This feature will assist in long term storage of hydrogen for upper stages that must sustain on-orbit storage or long coast times. Also, lunar flight and interplanetary missions with large hydrogen fuel loads will derive a benefit.

Significant density increases are possible with gelled hydrogen. A $10 \%$ density increase is possible with $10 \%$ added ethane or methane. These gellants are introduced into the hydrogen as frozen particles that form a gel structure in the hydrogen.13, 14 Appendix A provides some additional analyses of gelled hydrogen density and performance and some additional discussion of its benefits.

Specific analyses of the performance gains for various missions are dependent on the vehicle and mission design. Systems analyses performed for higher density hydrogen vehicles have shown that the reductions of the gross lift off weight (GLOW) for increased density hydrogen are very significant. In cases where another high density hydrogen, slush hydrogen was used, the density increased by $16 \%$, the GLOW was reduced by $10.2 \%$, or 102,000 $\mathrm{lbm} .18,19$ For airbreathing vehicles, such as the National Aerospace Plane (NASP), the estimated reduction in GLOW for slush hydrogen was from 20 to $50 \%$. Thus, a gelled hydrogen with a $10 \%$ density increase may deliver a significant fraction of these GLOW reductions and other subsystem mass savings. 20,21

\section{Experiment Description}

The experimental program included nanoparticulate gellant production, the synthesis and syneresis (settling) testing of gelled and metallized gelled hexane, design, construction, and testing of a cryogenic capillary rheometer, and the rheological characterization or liquid hydrogen.

Objectives. The principal objective was to explore the feasibility of a new class of gellant materials for advanced cryogenic gelled propellants. The goal was to demonstrate the synthesis and preparation of nanometerdimension polymer gellant materials which are capable of efficiently gelling cryogenic liquids. A second objective was to provide a preliminary evaluation of the rheological properties of candidate gelled formulations and determine their fluid properties.

\section{Gellant Sol-Gel Synthesis}

Sol-gel material synthesis methods were selected for the preparation of candidate advanced gellant materials. Sol-gel processing technology has been extensively studied and used to prepare a wide variety of finemicrostructure film, foam and powder materials. 22 The technology uses solutionbased polymer synthesis reactions and well established product drying/recovery methods for preparing multi-component materials with homogeneous molecules. The technology has several attractive features: it is readily scalable for producing large product volumes if eventually required, it uses commercially available precursors for starting materials, and it is uniquely capable of preparing 
combinational type materials like organoceramic polymers. This last feature is needed for preparing gellant materials with selectable chemical properties and affinities for fluids with widely differing polarities.

Gellant Synthesis. Nanoparticulate gellant was prepared in the same manner as that for the preparation of earlier polymer gellant material (BTMSE) described in Appendix B. Twenty (20) grams of BTMSE nanoparticulate gellant materials were produced using supercritical fluid processing. To verify the quality of gellant material that was produced, selected samples were subjected to physiochemical properties analyses, including determination of the specific surface area of the BTMSE aerogel product. The quality of material produced was comparable to that produced in the earlier work.

Table 1 shows the variation in the specific surfaces of different batches of gellant materials. Eleven batches were produced to determine the repeatability of the production runs. Past experimental results have indicated the need for gellant material with a specific surface area in the region of $800-900 \mathrm{~m}^{2} / \mathrm{g}$. Batch 1 fell short of this goal by a significant amount as this was the first experiment with the process, but almost all of the other batches produced the desired specific surface values.

Table 1

BET Surface Area Results

Gellant Batch No. Surface Area (m2/g)

$\begin{array}{rl}1 & 676 \\ 2 & 931 \\ 3 & 926 \\ 4 & 950 \\ 5 & \text { (test aborted) } \\ 6 & 1012 \\ 7 & 959 \\ 8 & 869 \\ 9 & 845 \\ 10 & 788 \\ 11 & 780\end{array}$

Syneresis Experiments. Metal particle and gellant syneresis effects were qualitatively studied. Settling is defined as the percentage of the volume that is clear (or without gellant) that is above the gelled liquid in its storage container. Using the cryogenic simulant hexane, settling effects were observed for both BTMSE gelled hexane and metallized gelled hexane (13.8 wt\% aluminum) under a variety of gravity loading environments ranging from 2 to $10 \mathrm{G}$ 's. Tables 2 and 3 list the results for the gelled and metallized gelled hexane experiments, respectively. The slight variations in the settling results are due to the variations in the gellant specific surface or strength.

The results appear to indicate the existence of a critical gellant concentration, above which no settling was observed. This value resides somewhere between 0.07 and $0.03 \mathrm{wt} \%$ of gellant. Furthermore, this critical value does not apparently change over those accelerations which were investigated, from 2 to 10 times that of gravity.

\section{Cryo-Rheometer for Metallized Hydrogen Gels}

The existing literature on hydrogen viscosity measurements describe techniques that involve oscillating disks, torsional disks, and a variety of fine capillary tubes.23-27 It was anticipated that these approaches would not be applicable to the metallized gelled hydrogen due to their non-Newtonian behavior. A direct measurement approach, using a cone-and-plate cryo-rheometer design, was therefore initially sought. Additional considerations for the design were the capability to condense liquid hydrogen, mix the metal additives and gellant materials with the liquid hydrogen, maintain temperature within a narrow liquid window of 15 to $20 \mathrm{~K}$ during the rheological measurements, maintain an oxygendepleted environment, and measure flow rate and viscosity in the low shear rates for rheological properties, such as yield point and pseudoplastic behavior. 
Table 2

Gelled Hexane Syneresis Results

Gellant Wt\% Results

Acceleration $=2$ gravities

$\begin{array}{ll}0.03 & 20 \% \text { Settling } \\ 0.05 & 0 \% \text { Settling } \\ 0.07 & 0 \% \text { Settling } \\ 0.10 & 0 \% \text { Settling }\end{array}$

Acceleration $=5$ gravities

$\begin{array}{ll}0.03 & 50-80 \% \text { Settling } \\ 0.05 & 30 \% \text { Settling } \\ 0.07 & \text { Side Loss of Gellant } \\ 0.1 & 0 \% \text { Settling }\end{array}$

Acceleration $=10$ gravities

$\begin{array}{ll}0.03 & 50 \% \text { Settling } \\ 0.05 & 0 \% \text { Settling } \\ 0.07 & 0 \% \text { Settling } \\ 0.10 & 0 \% \text { Settling }\end{array}$

Table 3

Metallized Gelled Hexane Syneresis Results: 10 Gravities Acceleration

Gellant Wt\% Results

$\begin{array}{ll}0.03 & 5 \% \text { Settling } \\ 0.05 & 5 \% \text { Settling } \\ 0.07 & 5 \% \text { Settling } \\ 0.10 & 5 \% \text { Settling }\end{array}$

The initial design was developed on the basis of the successful experience with cone/plate rheometers and preparing propane and ethane gels. These gels were mixed using an ultrasonic probe. The gelled hydrogen design involved modifying the existing rheometer to submerse a heat exchange chamber containing the cone-plate measuring element into a liquid helium dewar. The condensed hydrogen would then be mixed with the metallic additives and nanoparticulate gellant inside the housing with the ultrasonic agitation of the in-situ piezoelectric (PZT) crystals. However, preliminary experimentation revealed that adequate ultrasonic mixing could not be reliably attained, and that mechanical stirring would be required. The design was hence modified to allow the gel ingredients to be stirred in an external mixing chamber prior to transferring the hydrogen gel to the heat exchange chamber through an insulated delivery tube. The external mixer design was considered to be too complicated and its design could not ensure effective transfer of the gel due to the excessive thermal losses from the cryogenic (liquid helium) valves and long delivery tube. Therefore, the cone/plate rheometer design concepts were abandoned.

Capillary Flow Rheometer Design. The final design selected was a capillary flow rheometer which is typically used to measure flow behavior of fluids in the high shear rate region. The key elements consist of two internal mixing cups of known volume $(90 \mathrm{ml})$ connected with a transfer tube of predetermined inner diameter $(0.001 \mathrm{~m})$ and length $(1 \mathrm{~m})$. Each mixing cup is equipped with silicon diodes and heaters for temperature sensing and control. They are housed in a heat exchange chamber which is submerged in liquid helium inside a magnetic dewar. The interior of the heat exchange chamber is either filled with helium gas for thermal exchange between mixing cups and dewar, or in a vacuum to provide thermal isolation of the mixing cups. Hydrogen gas is condensed in the temperaturecontrolled buffers which function as liquid hydrogen reservoirs. The liquid hydrogen is mixed with metallic additives and nanoparticulate gellant in the mixing cups equipped with long-shaft stirrers and powered by twin external motors. An in-situ liquid level 
probe, which consists of a string of seriesconnected carbon resistors, is used to determine the volume of hydrogen gel inside each mixing cup.

The key measurement is the time required to expel a known volume of gel from one mixing cup to another. The gel expulsion is achieved through releasing helium gas into one of the two the mixing cups to establish a constant pressure gradient between the two mixing cups. These measurements provide the flow rate versus expulsion pressure ( $Q$ vs. $P$ ) profile for a given gel. The viscosity for Newtonian fluids can be determined using the Hagen-Poiseuille equation:

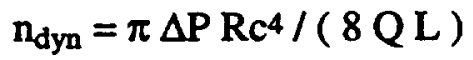

where $\mathrm{n}_{\mathrm{dyn}}$ is the dynamic viscosity, $\Delta \mathrm{P}$ is the pressure drop, $Q$ is the volumetric flow rate, and $R c$ and $L$ refer to the inner radius and the length of the delivery tube, respectively.

For power-law fluids:

$$
t=\Delta P R_{c} /(2 L)=K(\text { gamma-dot) } n
$$

gamma-dot - r (d $\Omega / d r)$

$\mathrm{n}_{\mathrm{dyn}}=\mathrm{K}($ gamma-dot) $\mathrm{n}-1$

where $t$ is the shear stress, $r$ is the cylinder radius in the gap of the rheometer, and $\Omega$ is the rotation rate of the rheometer cylinder. These equations allow the capillary rheometer shear rate results to be compared with those for cone and plate rheometers.

Cryogenic Rheometer Experiments and Results. A check-out run of the cryorheometer was conducted with liquid neon (normal boiling point [NBP] of $27.1 \mathrm{~K}$ ) and demonstrated that the system can safely be operated at liquid hydrogen temperatures. After this checkout, liquid hydrogen testing was conducted, followed by gelled hydrogen experiments. In the rheometer, the gelled hydrogen is formed by filling one cup with BTMSE, filling the other with hydrogen, and forcing the hydrogen into the BTMSE to mix the two. Enough BTMSE was used to produce gelled hydrogen with a 7-wt\% gellant loading: approximately 0.24 grams.

After thermal and chemical equilibria were attained (as evidenced by the temperatures becoming constant and by and zero pressure/gradient across the two cups), helium gas was introduced into the first mixer cup, thereby creating a positive pressure of up to $1,000 \mathrm{~Pa}$ which expelled the hydrogen gel into the second cup. A key parameter in determining viscosity using this device is the time required to expel a known volume of material from one mixing cup to the other via the capillary path. Material transfer is accomplished through releasing helium gas into the mixing cup which contains the sample, thus establishing a constant pressure gradient between the two mixing cups. By monitoring the liquid level probe inside the first cup, the amounts of hydrogen gel transferred was determined, where each incremental voltage increase corresponds to a rise in resistance of the level probe which reflects a drop in liquid level between the two sequential carbon resistors.

In the gelled hydrogen tests, approximately $48 \mathrm{~mL}$ of gelled hydrogen were transferred in 250 seconds. The steady state portion of this transfer was 120 seconds. Assuming Newtonian behavior, this transfer rate equals a viscosity of 0.048 to $0.116 \mathrm{mPa}-\mathrm{s}$ at a shear rate of $4,000 \mathrm{~s}^{-1}$. This is about $1.5 \mathrm{t}$ o 3.7 times higher than the viscosity of liquid hydrogen $(0.03 \mathrm{mPa}-\mathrm{s})$ measured in the hydrogen flow tests demonstrates the thickening effect. For comparison, a value of hydrogen viscosity of $0.023 \mathrm{mPa}$-s is reported in the literature for liquid hydrogen (at $14.5 \mathrm{~K}$ and $1 \mathrm{~atm}$ pressure), so there is some small discrepancy in the viscosity value. The shear rates and higher viscosities were not representative of those in a full-scale propulsion application, but they show a trend that implies that the gelled hydrogen will have a small viscosity difference from the ungelled 
hydrogen fuel under high velocity flow conditions.

On successful runs, a readily detectable stable transfer of fluid flowed through the capillary. Figures 1 and 2 illustrate the liquid hydrogen and gelled hydrogen transfers, respectively. Data were taken from liquid level sensors located in one of the two transfer cups connected via the capillary tube and translated into a total volume of transferred fluid. The transfer shown in Figure 1 depicts the transfer of $90 \mathrm{ml}$ of hydrogen in 270 seconds. A pressure drop of $351.5 \mathrm{~Pa}(0.051 \mathrm{psi})$ was required. For the gelled hydrogen experiment in Figure 2, the pressure drop for the transfer was $723.6(0.105 \mathrm{psi})$ and there were $48 \mathrm{ml}$ transferred in 250 seconds. A very smooth transfer occurred with the gelled hydrogen and the smoothness is attributed to the gellant creating and promoting a more laminar flow of the hydrogen. In the rheological flow experiments, the upstream cup was maintained at approximately 4824.3 to $6891.8 \mathrm{~Pa}(0.7$ to $1.0 \mathrm{psi}$ ) above atmospheric pressure and the downstream cup open to the ambient atmosphere. The temperature of the hydrogen in the experiment was $16 \mathrm{~K}$.

Table 4 summarizes the results of the seven experimental runs. The pressurization of the liquid beyond the yield point results in rapid flow through the capillary. Prior to reaching that point, however, pressure must first build up in the mixing cup to that yield point. Measurements of the pressure just prior to initiation of flow provides a direct measurement of the yield stress.

In the cryo-rheometer, yield stress was determined by a measurement of the capillary tube pressure drop, in terms of pounds per square inch. The pressure at which the flow is initiated corresponds to the yield stress associated with the yield point of the gellant molecular network. Table 5 provides the yield stress data for runs $7 \mathrm{a}$ and $7 \mathrm{~b}$ (with gelled hydrogen). Runs 7a and 7b are part of and related to Experiment 7 of Table 4. The yield stress is very low and would be easily overcome using the typical tank pressures of
Table 4

Cryo-Rheological Data Summary

Experiment \# $\begin{gathered}\text { Viscosity } \\ (\mathrm{mPa}-\mathrm{s})\end{gathered} \quad$ Comments

Liquid hydrogen

\begin{tabular}{lll}
\hline 1 & 0.0314 & $\begin{array}{l}\text { Successful } \\
\text { Baseline Run }\end{array}$ \\
2 & 0.0319 & \\
3 & 0.0313 & \\
\hline 4 & 7 w\% BTMSE/Liquid Hydrogen \\
\hline 5 & 0.0843 & $\begin{array}{l}\text { Some Icing } \\
\text { Encountered }\end{array}$ \\
& 0.0482 & $\begin{array}{l}\text { Icing } \\
\text { Encountered }\end{array}$ \\
6 & 0.0751 & $\begin{array}{l}\text { Some Icing } \\
\text { Encountered }\end{array}$ \\
7 & & $\begin{array}{l}\text { No Icing } \\
\text { Detected }\end{array}$ \\
\hline
\end{tabular}

Table 5

Gelled Hydrogen Yield Stress Data

$\begin{array}{lll}\text { Experiment } & \begin{array}{l}\text { Initial Can } \\ \text { Pressure } \\ \text { (psig) }\end{array} & \begin{array}{l}\text { Measured } \\ \text { Yield Stress } \\ \text { (psi) }\end{array}\end{array}$

$\begin{array}{lll}7 \mathrm{a} & 1.045 & 1.1\end{array}$

$\begin{array}{lll}7 b & 0.720 & 0.8\end{array}$ 
current pump-fed or pressure-fed propulsion systems.

\section{Discussion}

These results demonstrated the effectiveness of polymer-derived gellants for cryogenic propellants, and verified the approach of using nanoparticulates to gel cryogenic fluids.

The current experiments were conducted under a very restricted set of temperatures and pressures, and many of the conditions were not completely representative of actual propulsion applications. Extremely small volumes of fluid were tested with the capillary rheometer: $48 \mathrm{ml}$. Also the test pressures were low: only about 16 psia. Also the test temperature was about $16 \mathrm{~K}$. No metallized gelled hydrogen testing was conducted, though testing of the metallized gelled hexane was conducted and proved some of the syneresis results at high $\mathrm{G}$ levels. Gellants are extremely effective in other hydrocarbons such as hexane, etc. The relatively low percentage needed (0.03-0.07 wt\% BTMSE in hexane) bodes well for hydrocarbons with higher boiling points.

The yield stress for gelled hydrogen was measured in the region of 1 psi. Viscosity after reaching the yield point of the gel network was found to decrease rapidly, approaching that of liquid hydrogen itself in the range of 0.046 to $0.116 \mathrm{mPa}-\mathrm{s}$, allowing for nearly unrestricted flow after reaching the yield point. This thixotropic gel, with the very low yield stress will be required for conventional propellant transfer from propellant tankage to the rocket or airbreathing engines. The low yield point of the gel will also minimize the number changes to existing feed system and engine designs to use gelled propellants.

There are many possibilities for gelling liquid hydrogen and the selection of the gellant will depend on the mission needs; methane and ethane are advantageous and nanoparticulates are also a strong contender if the cost is reduced. The best possibilities for making a gelled propellant work in the near term are the methane or ethane gellant and using this formulation to demonstrate the effectiveness of gelled hydrogen to eliminate propulsion leakage, increase safety, increase propellant density, reduce propellant slosh, and potentially improve performance. Gelled hydrogen has great potential for improving future propulsion systems, especially airbreathing Earth-to-Orbit vehicles.

\section{Conclusions}

A nanoparticulate gellant material was synthesized and the rheological characterization of cryogenic propellants after gelation were measured. However, only one gelled hydrogen formulation was characterized. Measurements of viscosity, yield stress, and syneresis under various high gravity levels confirmed stable gelled hexane and gelled hydrogen fuels and potentially favorable theological properties.

To evaluate the gelling efficiency of polymer-derived nanoparticulates for extremely low temperatures, a $15-\mathrm{K}$ capillary-flow rheometer was designed and assembled. A demonstration run was conducted with liquid hydrogen gel using a BTMSE gellant mass fraction of $7 \mathrm{wt} \%$ and the gel exhibited a viscosity of 0.048 to $0.116 \mathrm{mPa}-\mathrm{s}$ at a moderate shear rate of 4,000

$\mathrm{s}^{-1}$. This is approximately only about 1.5 to 3.7 times higher than that for liquid hydrogen alone.

Experiments to characterize the theology of gelled and metallized gelled hexane were also conducted. Syneresis and stability tests was conducted with gelled hexane and metallized gelled hexane (13.6-wt\% Al) and a critical concentration of gellant, at a loading of 0.03 to $0.07 \mathrm{wt} \%$ BTMSE, was able to establish a stable gelled fuel during high acceleration testing at 2,5 and 10 gravities.

\section{Concluding Remarks}

The low shear rates and consequently higher viscosities of the gelled hydrogen are 
not representative of those expected in a fullscale propulsion application, but they show a trend that implies that the gelled hydrogen will have a minimal viscosity difference from the ungelled hydrogen fuel under high velocity flow conditions.

The objective of any future gellant optimization would be to produce a gellant material that is efficient for gelling liquid hydrogen at concentrations less than 2 to $3 \mathrm{wt}$ $\%$. At these concentration levels gellant material will have a much-reduced thermodynamic and engine system performance penalty over the currently-required 7 to $8 \mathrm{wt} \%$ gellant level.

\section{Acknowledgements}

This paper describes work conducted by TRW Space and Technology Division under Contract NAS3-26714 during the period of September 1992 to December 1994. The project was managed by Drs. John A. Starkovich and Scott Adams of TRW. Major contributors included the following:

Dr. William Davison for gellant synthesis, Hareesh Thridandam for the rheological measurements and data analysis, William Burt for the cryo-rheometer design, Hsiao-Hu Peng for the cryo-rheometer fabrication and demonstration, Dr. Scott Adams for hydrogen gel rheology. Administrative review was conducted by Myrrl J. Santy, Manager of TRW's Advanced Materials and Products Department and NASA project management was provided by Bryan $A$. Palaszewski.

\section{References}

1) McKinney, C.D., and Tarpley, W., "Gelling of Liquid Hydrogen," Technidyne, Inc., Contract Number NAS3-4186, NASA CR-54967, RR 6649, June 1, 1966.
2) Keller, C.W., "A Study of Hydrogen Slush and/or Hydrogen Gel Utilization Vol. 1: Saturn S-4C Manned Mars Flyby Vehicle Application Study", NASA CR-98936, NAS8-20342, Lockheed Missiles and Space Co., K11-67-1K- Vol. 1, October 31, 1968.

3) Keller, C.W., "A Study of Hydrogen Slush and/or Hydrogen Gel Utilization Vol. II: Test Program 41.5-inch Diameter Tank", NASA CR-98935, NAS8-20342, Lockheed Missiles and Space Co., K-11-67-1K-Vol. 2, October 31, 1968.

E. Van der Wall, "Carbon Compounds /Liquid Hydrogen Fuels", Aerojet Liquid Rocket Company Final Report, Technical Report FR02-W396, October 1970, Contract SNP-1.

"Characteristics of a Gelled Liquid Hydrogen Polyphenylene Oxide (PPO) Foam Open-Cell Insulation System," General Dynamics, Report Number GDCA 632-3-169, Contract NAS827203, February 15, 1973.

6) Wong, W., “Advanced Gellant Materials for Metallized Cryogenic Propellants," TRW Final Report, NAS3-25793, September 1993.

7) Wong, W., Starkovich, J., Adams, S., and Palaszewski, B., "Cryogenic Gellant and Fuel Formulation for Metallized Gelled Propellants: Hydrocarbons and Hydrogen with Aluminum," AIAA 94-3175, presented at the 30th AIAA/ASME/SAE/ASEE Joint Propulsion Conference, June 1994.

8) R. Wiswell and M. Huggins, "Launch Vehicle and Upper Stage Liquid Propulsion at the Astronautics Laboratory (AFSC) - A History Summary", AIAA 90-1839 
9) Palaszewski, B., "Metallized Gelled Propellant Experiences and Lessons Learned: Oxygen /RP-1/Aluminum Rocket Engine Testing," in CPIA Publication 627, 1995 Gel Propulsion Technology Symposium, Huntsville, AL, September 1995.

10) Palaszewski, B. and Zakany, J., 'Metallized Gelled Propellants: Oxygen /RP-1 /Aluminum Rocket Combustion Experiments," AIAA 95-2435, presented at the 31st AIAA/ASME/SAE Joint Propulsion Conference, San Diego, CA , July 1995.

11) B. A. Palaszewski, "Metallized Propellants for the Human Exploration of Mars", Case for Mars IV Conference, Boulder, CO, June 4-8, 1990

12) Palaszewski, B. and Powell, R., "Launch Vehicle Propulsion Using Metallized Propellants," NASA-Lewis Research Center, AIAA 91-2050, presented at the 27th AIAA/ASME/SAE Joint Propulsion Conference, Sacramento, CA , June 24-27, 1991 , also in AIAA Journal of Propulsion and Power, Vol. 10, No. 6, Nov.-Dec. 1994, pp. 828-833.

13) G. Giola, W. Chew, D. Ryder, "Propulsion Systems Hazards Evaluation and Liquid/Gel Propulsion Component Development Program", Volume IV - Executive Summary, TRW, Inc., Final Report, Contract Number DAAH-01086-C-0114, Technical Report CR-RD-PR-90-1, December 1989.

14) N. Munjal, B. Gupta, and M. Varma, "Preparative and Mechanistic Studies on Unsymmetrical Dimethyl HydrazineRed Fuming Nitric Acid Liquid Propellant Gels, "in Propellants. Explosives, and Pyrotechnics, 10, 4, $111,1985$.
15) Escher, W., Hyde, E, and Anderson, D., "A User's Primer for Comparative Assessments of All-Rocket and Rocket based Combined Cycle Propulsion Systems for Advanced Earth-to-Orbit Space Transport Applications," AIAA 95-2474, presented at the 31st AIAAVASME/SAE Joint Propulsion Conference, San Diego, CA , July 1995.

16) Escher, W., "Motive Power for Next generation Space Transports: Combined Airbreathing and Rocket Propulsion," AIAA 95-6076, AIAA 6th International Aerospace Planes and Hypersonics Technologies Conference, Chattanooga, TN, April 1995.

17) Siebenhaar, A., and Bulman, M., "The Strutjet Engine: The Overlooked Option for Space Launch," AIAA 95-3124, presented at the 31st AIAAASME/SAE Joint Propulsion Conference, San Diego, CA , July 1995.

18) Elwart, $R$, and Dergance, $R$., "Cryogenic Propellant Densification Study," Martin Marietta Corp., NASA CR-159483, MCR-78-586, November 1978.

19) Wilhite, A, et al, "Advanced Technologies for Rocket Single Stage to Orbit Vehicles," AIAA Journal of Spacecraft and Rockets, Voule 28, Number 6, November-December 1991, pp. 646-651.

20) Hardy, T., and Whalen, M., "Technology Issues Associated with Using Densified Hydrogen for Space Vehicles," AIAA 92-3079, AIAA 28th Joint Propulsion Conference, Nashville, TN, July 1992.

21) Friedlander, A., Zubrin, R., and Hardy, T., "Benefits of Slush Hydrogen for Space Missions," NASA Technical Memorandum 104503, October 1991. 
22) C. J. Brinker and G. W. Scherer, "SolGel Science," Academic Press, 1990.

23) C. C. Mills, "Rheology of Disperse Systems", Pergamon Press, New York, 1959.

24) D. E. Diller, "Measurement of the Viscosity of Para-Hydrogen", J. of Chem. Phys., 42 (6), 2089, 1965.

25) H. E. Johns, "The Viscosity of Liquid Hydrogen, "Can. J. Res. 17A, 221, 1939.

26) A. Van Itterbeek, H. Zink, and O. Van Paemel, "Viscosity Measurement in Liquified Gases", Cryogenics, 2, 210 , 1962.

27) N. S. Rudenko and V. G. Konareva, Zh. Fiz. Khim., 37, 2761, 1963. 


\section{Liquid hydrogen transfer experiment 2}

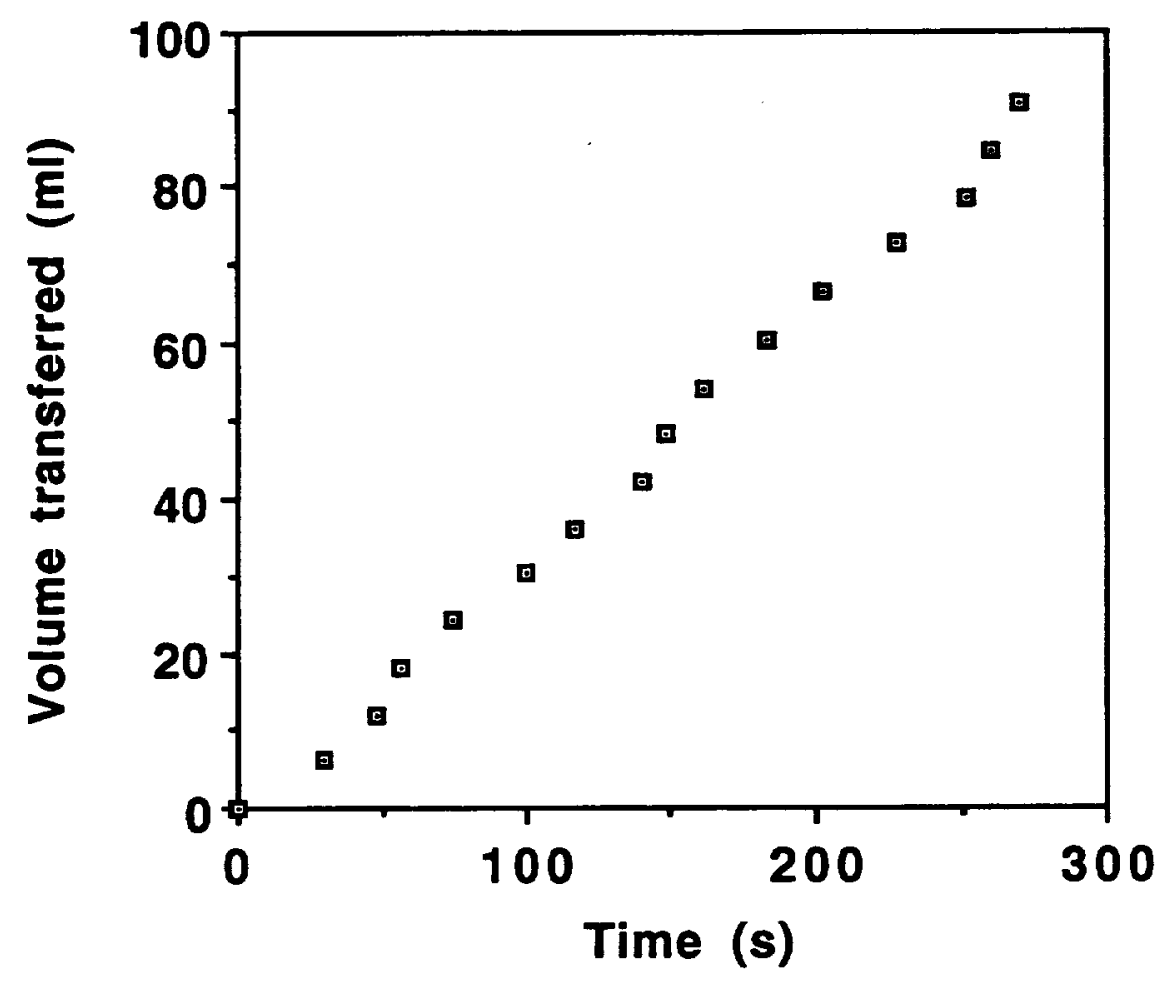

Figure 1: Liquid Hydrogen Capillary Transfer Curve (Experiment \#2) 


\section{Gelled hydrogen transfer experiment 6}

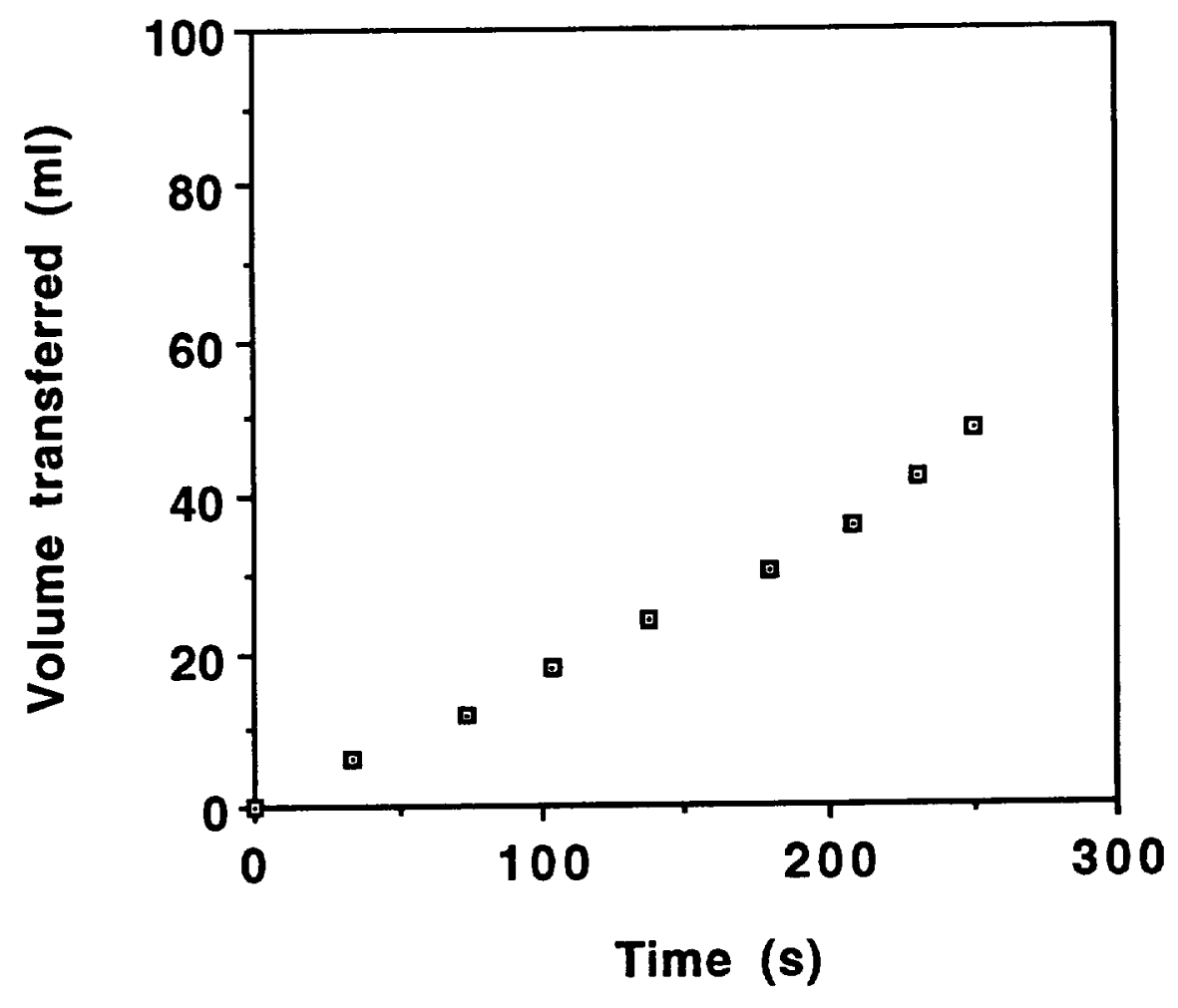

Figure 2: Gelled Hydrogen (BTMSE = 7-wt\%) Capillary Transfer Curve (Experiment \#6) 


\section{Appendix A}

Gelled Hydrogen Density and Specific Impulse with Methane Gellants

The Isp of a gelled hydrogen powered vehicle may also increase over a liquid hydrogen powered vehicle, in some cases. Figure $A 1$ shows the $I_{s p}$ variations for gelled hydrogen over an methane $\left(\mathrm{CH}_{4}\right)$ percentage range of $0 \%$ to $70 \%$. This range was selected to cover the typical values of added gellant percentages investigated in past experimental work. Also, these gellant percentages may offer attractive density increases for future vehicles. Table A1 provides the mixture ratios for the different methane loadings. Oxygen is the oxidizer, the expansion ratio is 40:1 and the chamber pressure is 2250 psia. A 94\% Isp efficiency is used to compute the delivered $\mathrm{I}_{\text {sp. }}$ The maximum Isp occurs at a $5 \% \mathrm{CH}_{4}$ loading and this performance level is 4 seconds higher than ungelled $\mathrm{O}_{2} / \mathrm{H}_{2}$.

\section{Gelled Hydrogen Rocket Performance}

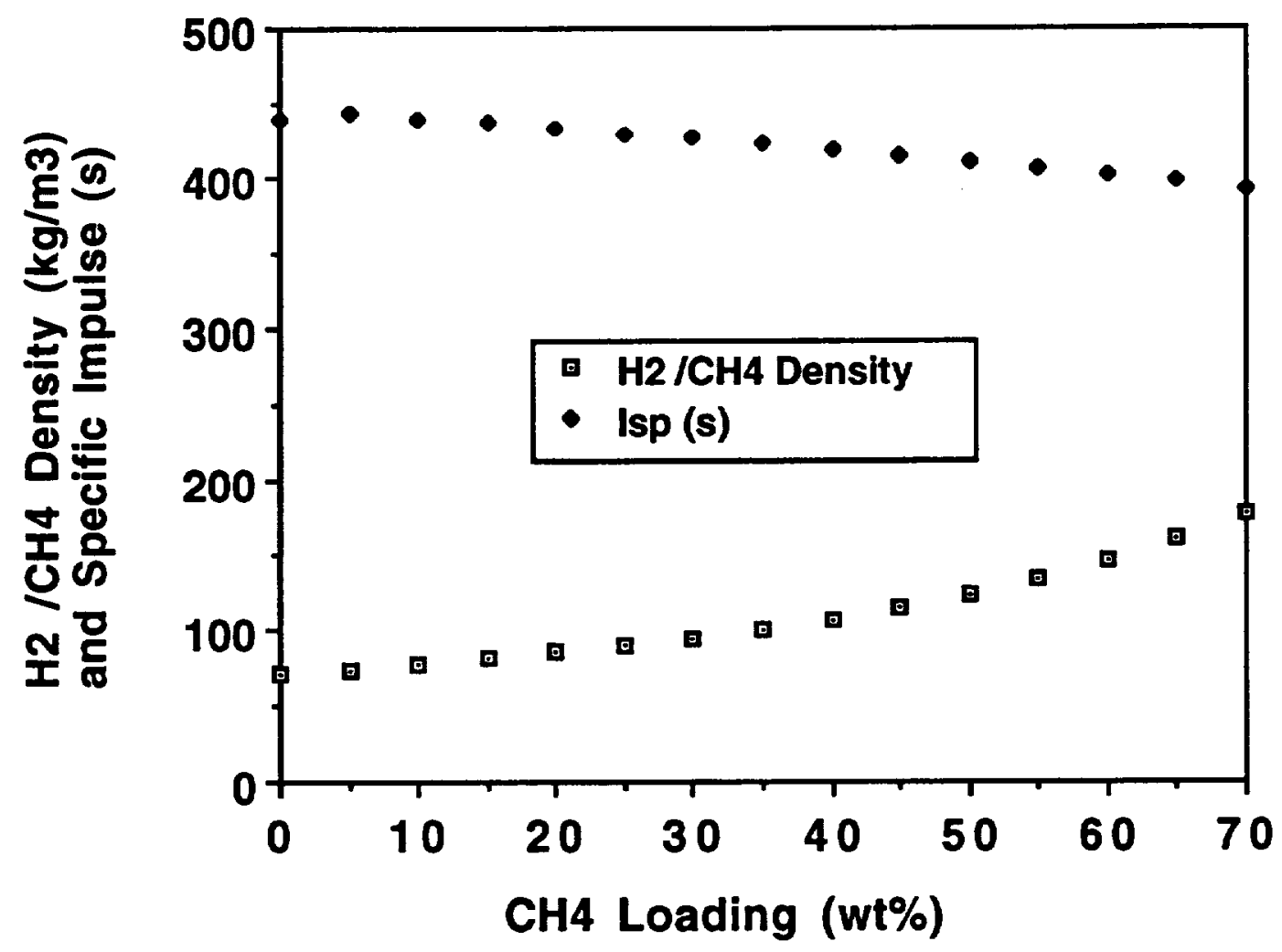

Figure A1: Gelled Hydrogen Rocket Engine Specific Impulse

(Oxygen as oxidizer, 2250 psi chamber pressure, expansion ratio $=40: 1$ ) 
Table A1

Gelled $\mathrm{H}_{2} / \mathrm{CH}_{4}$ Mixture Ratios and Densities

\begin{tabular}{ccc}
$\mathrm{CH}_{4}$ Loading (wt\%) & Mixture Ratio & Density $\left(\mathrm{kg} / \mathrm{m}^{3}\right)$ \\
\hline 0.0 & 6.0 & 70.00 \\
5.0 & 4.2 & 73.17 \\
10.0 & 4.2 & 76.63 \\
15.0 & 4.2 & 80.44 \\
20.0 & 4.3 & 84.65 \\
25.0 & 4.3 & 89.33 \\
30.0 & 4.3 & 94.55 \\
35.0 & 4.2 & 100.41 \\
40.0 & 4.3 & 107.06 \\
45.0 & 4.2 & 114.65 \\
50.0 & 4.2 & 123.39 \\
55.0 & 4.1 & 133.58 \\
60.0 & 4.1 & 145.60 \\
65.0 & 4.0 & 160.00 \\
70.0 & 4.0 & 177.56 \\
\hline
\end{tabular}

\section{Other benefits of gelled hydrogen}

For airbreathing propulsion, the largest volume of the vehicle is the hydrogen tank. Therefore, the volume reductions enabled by gelled hydrogen may be significant and this effect cascades into other subsystems for significant further mass and volume reductions. The subsystems that are affected are the aerodynamic thermal protection systems, cryogenic insulation, structural masses, and all of the other subsystems influenced by the hydrogen fuel tankage. A higher viscosity for the gel will also reduce the slosh modes in a propellant tank. Slosh baffle size and mass reductions are therefore possible by using gelled propellants. These masses can be very significant for a launch vehicle application.

Another option with gelled propellants is adding metal particles. Metallized gelled propellants may have modestly higher specific impulses $\left(\mathrm{I}_{\mathrm{sp}}\right.$ increases of 5 to $6 \mathrm{lb}_{\mathrm{r}}-\mathrm{s} / \mathrm{lb} \mathrm{b}_{\mathrm{m}}$ for $\mathrm{O}_{2} / \mathrm{H}_{2}$ /Al system, $60 \mathrm{wt} \% \mathrm{Al}$ in the $\mathrm{H}_{2} / \mathrm{Al}$ fuel) compared to nonmetallized hydrogen fuels. For proposed NASA Mars evolution and expedition missions, it has been estimated that metallized gelled $\mathrm{O}_{2} / \mathrm{H}_{2} / \mathrm{Al}$ propellants can result in a 20 to $33 \%$ improvement in surface payload delivery capability. 6 More importantly for $\mathrm{O}_{2} / \mathrm{RP}-1 / \mathrm{Al}$ and NTO $/ \mathrm{MMH} / \mathrm{Al}$ propellants, adding metal can deliver considerably higher propellant density, depending on the application. Hence, both the tankage mass as well as the overall propulsion system dry mass can be substantially reduced. The propellant density increases and their attendant $I_{\text {sp }}$ changes with the aluminum additives allow a payload increase of 14 to 35 percent by replacing the Space Shuttle Solid Rocket Booster with a Liquid Rocket Booster using $\mathrm{O}_{2} / \mathrm{RP}-1 / \mathrm{Al}$ and NTO/MMH /Al, respectively. ${ }^{7}$ 


\section{Appendix B \\ Nanoparticulate Gellants: BTMSE Formulation}

The candidate gellant materials were prepared from organic compound polymerization reactions carried out in an alcohol solution. The starting compounds used in the synthesis reactions were boron and silicon esters of ethyl and methyl alcohol. These compounds are known as alkoxides and are commonly used reagents in sol-gel synthesis of various glass and ceramic composition materials. Alkoxides containing ethyl (BTMSE) hydrocarbons were also used for synthesis purposes where an organic group was desired in the final polymer gellant material. The polymerization reactions were initiated through acid-catalyzed hydrolysis of the alkoxide compound. Illustrative examples of the overall reactions involved in the synthesis of single and copolymer composition products are given in Refs. 1 and 2 . The hydrolysis and polymerization reactions proceed to form weakly-coherent, translucent alcogels in the reaction medium. Gel formation typically required anywhere from a few minutes to 24 hours depending on the catalyst, monomer concentration and temperature conditions employed.

Product Drying and Recovery. The precursors react to form, coherent polymer alcogels from homogeneous solutions containing as low as 0.05 molar monomer. These polymer alcogels consist of delicate three-dimensional structural networks that cannot be dried using conventional methods, such as vacuum bake and oven heating since these methods can lead to high surface tension forces at the solid-fluid interface and cause the networks to collapse. Two-zero surface tension drying techniques, freeze-drying and supercritical fluid processing, were used to recover products for this study. The freeze drying involves solvent freezing followed by evaporation of the frozen solvent at reduced pressure. A commercial unit having a processing capability of 5 liters was used in this study. Critical fluid processing involves the use of a fluid such as $\mathrm{CO}_{2}$ in a supercritical state. By raising the pressure and temperature above the critical point of the exchange fluid ( $304.2 \mathrm{~K}$ and $73 \mathrm{~atm}$ for $\mathrm{CO}_{2}$ ), it is possible to extract the solvent from the alcogel without encountering significant surface tension forces at the solid-fluid interface. Nanoparticulate gellant materials with large specific surface areas were successfully prepared using both methods.1,2

$$
\begin{aligned}
& m \mathrm{~B}\left(\mathrm{OCH}_{3}\right)_{3}+3 \mathrm{~m} \mathrm{H}_{2} \mathrm{O} \rightarrow \mathrm{m} \mathrm{H}_{3} \mathrm{BO}_{3}+3 \mathrm{~m} \mathrm{CH}_{3} \mathrm{OH} \\
& \text { Boric Acid Methanol } \\
& n \mathrm{Si}\left(\mathrm{OC}_{2} \mathrm{H}_{5}\right)_{4}+4 \mathrm{n} \mathrm{H}_{2} \mathrm{O} \rightarrow \mathrm{n} \mathrm{Si}(\mathrm{OH})_{4}+4 \mathrm{n} \mathrm{C}_{2} \mathrm{H}_{5} \mathrm{OH} \\
& \text { Silanol Ethanol } \\
& \mathrm{HO}[-\mathrm{B}(\mathrm{OH}) \mathrm{O}]_{m}\left[-\mathrm{Si}(\mathrm{OH})_{2} \mathrm{O}\right]_{n} \mathrm{H}
\end{aligned}
$$

Linear borosilicate polymer

$$
\begin{array}{ccc}
\mathrm{m} \mathrm{H}_{3} \mathrm{BO}_{3}+\mathrm{n} \mathrm{Si}(\mathrm{OH})_{4} & \rightarrow & \text { or } \\
& & {[\mathrm{B} 2 \mathrm{O} 3]_{\mathrm{m} / 2}\left[\mathrm{SiO}_{2}\right]_{\mathrm{n}}} \\
& \text { Crosslinked borosilicate polymer }
\end{array}
$$




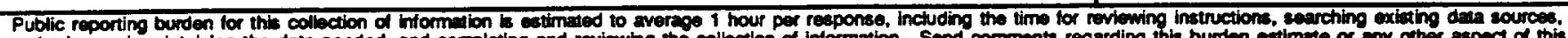
gathering and matntaining the deta neoded. and completing and reviowing the collecton of information. Send comments regarding this burden extimate or any other aspect of this collection of information, including suggestione for reducing this burden, to Washington Headquarters Services. Directorato for Information Operations and Reports, 1215 beter

\begin{tabular}{l|l|l|} 
1. AGENCY USE ONLY (Leave blank) & 2. REPOAT DATE & 3. REPORT TYPE AND DATES COVERED
\end{tabular}

4. TITLE AND SUBTIRE 5. FUNDING NUMBERS

Nanoparticulate Gellants for Metallized Gelled Liquid Hydrogen With Aluminum

\section{AUTHOR(S)}

John Starkovich, Scott Adams, and Bryan Palaszewski

WU-252-50-01

7. PERFORINMG ORGANIZATION NAME(S) AND ADDRESS(ES)

National Aeronautics and Space Administration

Lewis Research Center

Cleveland, Ohio 44135-3191

9. SPONSORINGMONITORING AGENCY NAME(S) AND ADDRESS(ES)

National Aeronautics and Space Administration

Washington, D.C. 20546-0001
8. PERforming organzation REPORT NUMBER

E-10354

11. SUPPLEMENTARY NOTES

Prepared for the 32nd Joint Propulsion Conference and Exhibit, Lake Buena Vista, Florida, July 1-3, 1996. John Starkovich and Scott Adams, TRW Space and Electronics Group, Redondo Beach, Califomia (work funded by NASA Contract NAS3-26714); Bryan Palaszewsici, NASA Lewis Research Center. Responsible person, Bryan Palaszewski, organization code 5310, (216) $977-7493$.

12a. DISTRIBUTIONAVAILABILTY STATEMENT 12b. DISTRIBUTION CODE

Unclassified - Unlimited

Subject Category 20

This publication is available from the NASA Center for AeroSpace Information, (301) 621-0390.

13. ABSTRACT (Maximum 200 words)

Gelled liquid hydrogen was experimentally formulated using sol-gel technology. As a follow-on to work with cryogenic simulants, hydrogen was gelled with an alkoxide material: BTMSE. Initial results demonstrated that gellants with a specific surface area of $1000 \mathrm{~m}^{2} / \mathrm{g}$ could be repeatably fabricated. Gelled hexane and metallized gelled hexane (with 13.8wt\% Al) were produced. Propellant settling testing was conducted for acceleration levels of 2 to 10 times normal gravity and a minimum gellant percentage was determined for stable gelled hexane and metalized gelled hexane. A cryogenic capillary rheometer was also designed, constructed, and used to determine the viscosity of gelled hydrogen. Small volumes of liquid hydrogen were gelled with a 7- to 8-wt\% gellant level. The gelled $\mathrm{H}_{2}$ viscosity was 1.5 to 3.7 times that of liquid hydrogen: 0.048 to $0.116 \mathrm{mPa}$-s versus $0.03 \mathrm{mPa}$-s for liquid $\mathrm{H}_{2}$ (at $16 \mathrm{~K}$ and approximately 1 atm pressure).

14. SUBJECT TERMS

Gellants; Gelled propellants; Metallized gelled propellants; Liquid hydrogen 15. NUMBER OF PAGES 18 16. PRICE CODE A03

17. SECUATY CLASSIFICATION OF REPORT Unclassified

18. SECURITY CLASSIFICATION
OF THIS PAGE
Unclassified

19. SECURITY CLASSIFICATION OF ABSTRACT Unclassified 


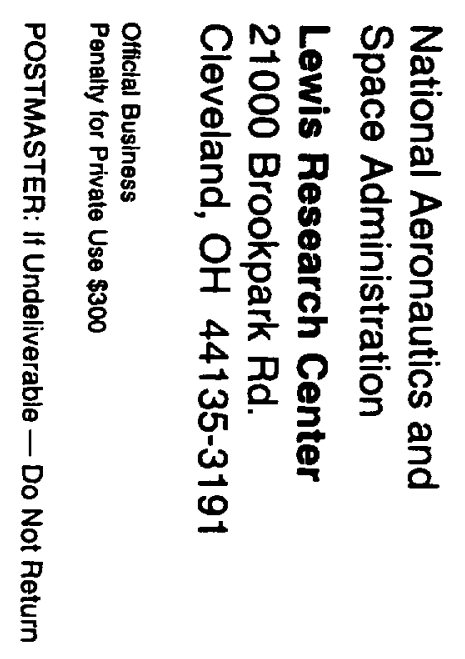

